\title{
Presentation rates and keywords in vocabulary learning
}

\author{
JAMES W. HALL, WILLIAM L. OWENS, and KIM P. WILSON \\ Northwestern University, Evanston, Illinois
}

\begin{abstract}
In Experiment 1, vocabulary learning for subjects given typical study instructions was higher for lists presented twice at a 4-sec rate than for lists presented once at an 8-sec rate; subjects in a mnemonic condition reported being unable to implement the mnemonic keyword method at the 4-sec rate. In Experiment 2, keyword subjects were superior to nonmnemonic subjects when presented with lists one time at a 9-sec rate, but subjects given three list presentations at a 3-sec rate without mnemonic instructions were still higher. The common practice in keyword experiments of imposing presentation rates on both the nonmnemonic and the keyword conditions appears to yield a distorted picture of the relative effectiveness of these conditions in more typical situatons wherein presentation-rate constraints are absent.
\end{abstract}

The present experiments addressed questions concerning optimal presentation conditions for simple vocabulary learning, that is, for learning brief meaningful verbal responses to unfamiliar stimulus words, as in foreign language study. Our specific interest was in the extent to which such learning, both with and without special mnemonic (keyword method) instructions, is affected by the rate and frequency of list presentation.

There was reason to suspect that vocabulary learning is sensitive to both presentation rate and frequency of list presentation. Earlier studies led Calfee and Anderson (1971) to propose that the optimal rate for paired-associate learning (PAL) is between 2 and $4 \mathrm{sec}$. In a more recent experiment by Hall, Smith, Wegener, and Underwood (1981, Experiment 3), PAL was higher with three list presentations at a 2-sec rate than with one at a 6-sec rate. There also was reason to think that rates that are optimal for vocabulary learning under ordinary conditions may be faster than is optimal when mnemonic devices are used. Experiments by Bugelski (e.g., 1970) and Wood (1967) converged upon the conclusion that at least several seconds are required to apply mnemonic techniques involving visual imagery to PAL; more recently, Bellezza (1981) and Higbee (1977) reiterated the need for relatively low presentation rates when mnemonics are being used. Accordingly, in most studies examining the effectiveness of the most common mnemonic for simple vocabulary learning, the keyword method (see Atkinson, 1975), quite slow (10 sec or slower) rates of presentation have been used.

The keyword method for simple vocabulary learning involves two stages. First the subject forms an association between the unfamiliar stimulus word and some familiar (ideally, concrete) English word that is similar

We thank the Wisconsin Center for Educational Research, Noel Kullavanijaya, Kevin Fearn, Ginny Neal, and Dorothy Egener. Requests for reprints should be sent to James W. Hall, Department of Psychology, Northwestern University, Evanston, IL 60201. in sound or spelling to the stimulus word. That familiar word acts as a mediator between the stimulus word and the response and is known as the keyword. Second, a compound visual image involving the referents of the keyword and of the response is generated. The idea is that at the time of test the simulus word will elicit the keyword, the keyword will elicit the image, and the learner will inspect the image to find the response term.

Given the complexity of the keyword mnemonic, it is not difficult to understand why unusually slow rates of presentation have so often been used with this method. What may be problematic is that the same slow presentation rates have been imposed on the nonmnemonic control conditions in most keyword experiments. If the optimal rates of presentation do differ markedly for vocabulary learning with and without mnemonic instructions, then this practice would lead to a distortion of the relative effectiveness of the two conditions under nonlaboratory conditions in which no presentation-rate constraints are imposed on the learner. In particular, it would lead to an overestimate of the effectiveness of the keyword method outside the laboratory. It was this possibility that led us to conduct the following experiments.

\section{EXPERIMENT 1}

\section{Method}

Sixteen Northwestern University undergracuates, screened to eliminate subjects with competence in Spanish, were assigned to each of two conditions (keyword and control). Each subject was presented with a practice list of 12 Spanish-English noun pairs (e.g., LADRON-ROBBER) and then with four lists of 22 such pairs. The lists were presented via a slide projector. For keyword subjects, a keyword was placed in parentheses between the Spanish and English words and the practice list was preceded by an explanation and examples of the method and instructions to use it. The instructions and items were similar to ones in earlier keyword studies (e.g., Hall, Wilson, \& Patterson, 1981). The control subjects were simply urged to try their best. Following the instructions, two consecutive lists were presented once at an 8-sec rate and two were presented twice each at a 4-sec rate, with order of presentation rate coun- 
terbalanced. After presentation of each list, subjects were given 2 min to write in the English equivalents for the 22 Spanish words, which were printed in a column, reordered, on a test sheet.

\section{Results}

Only 5 keyword subjects participated before that condition was discontinued. This was done because all 5 reported an inability to implement the keyword method at the 4-sec rate, and 4 became so agitated that they interrupted the session. One control subject was eliminated because we found later that he possessed some competence in Spanish. The statistical results, then, pertain to 15 subjects given standard study instructions. The criterion for statistical significance here and in Experiment 2 was $p<.05$.

The pattern of results was the same for the two lists in each rate condition, so performance was summed across them and a presentation rate $\times$ order ANOVA was applied. The only significant effect was rate $[F(1,13)=$ $14.88, M S e=32.55$ ]. The recall means were 28.27 (out of 44) for the 4-sec condition and 20.20 for the 8-sec condition, giving a $40 \%$ advantge to the former over the latter.

\section{EXPERIMENT 2}

In Experiment 2, we compared effectiveness of keyword instructions with a 9-sec presentation rate with effectiveness of standard study instructions with a 9-sec and a 3-sec rate. Both delayed and immediate retention were examined.

\section{Method}

Subjects studied and recalled brief definitions of rare English words under one of three conditions: three list presentations at a 3-sec rate with standard instructions, one presentation at a 9-sec rate with standard instructions, and one presentation at a 9-sec rate with keyword instructions. Twenty Northwestern students were assigned to each of the three conditions. Each subject was given instructions and a brief practice session in accord with his or her study condition. Then two consecutive 22 -item lists were presented, each followed by a paced test in which the rare words were presented, reordered, at a 9-sec rate. A second (delayed by about $7 \mathrm{~min}$ ) test then was given on the List 1 items. Instructions, study lists, and test items were presented on a monitor under control of an Apple II microcomputer, and subjects wrote their definitions on a separate numbered answer sheet. At the close of the session the subjects in the keyword condition indicated the percentage of items on each list for which they had used the keyword method by checking one of the following: $100,90-99,80-89,70-79,60-69,50-59$, or $<50$.

The items were words used by other experimenters combined with others found in a standard English dictionary (e.g., PANOPLY [PAN] ARMOR, SEQUACIOUS [GRACIOUS] SUBSERVIENT). In selecting words, no attention was paid to concreteness or ease of keyword generation; the only concern was that they be unfamiliar to most subjects. Keywords were generated and agreed upon by two of us and were inserted, in parentheses, between the rare word and its one- or twoword definition during study presentation.

\section{Results}

Every subject in the keyword condition reported use of the keyword on at least $60 \%$ of the items on each list. For List 2, which we consider to be the crucial one, the modal use was $80 \%-89 \%$.
Table 1

Experiment 2 Recall Means and Standard Deviations (SDs)

\begin{tabular}{|c|c|c|c|c|c|c|}
\hline \multirow[b]{3}{*}{ List } & \multicolumn{6}{|c|}{ Presentation Conditions } \\
\hline & \multicolumn{2}{|c|}{ Standard $3 \times 3$} & \multicolumn{2}{|c|}{ Standard $1 \times 9$} & \multicolumn{2}{|c|}{ Keyword $1 \times$} \\
\hline & Mean & $S D$ & Mean & $S D$ & Mean & $S D$ \\
\hline 1 & 15 & 3.31 & 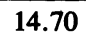 & 2.77 & 13.80 & 3.46 \\
\hline 2 & & 2.7 & & 4.17 & 16.50 & 2.50 \\
\hline 1 (Retest) & 15.90 & 3.91 & 13.45 & 3.02 & 13.00 & 3.84 \\
\hline
\end{tabular}

The learning data are summarized in Table 1. A $2 \times$ 3 (presentation condition) ANOVA yielded significant effects for presentation method $[F(2,57)=11.10, M S e=$ $16.15]$, for lists $[F(1,57)=10.54, M S e=4.10]$, and for the interaction between them $[F(2,57)=7.34, M S e=$ 4.10]. Because of the apparent learning-to-learn for the 3sec and keyword conditions (i.e., the substantial increase in performance from List 1 to List 2), it seemed most appropriate to examine List 2 performance separately. For that list, performance in the 3 -sec condition was $38 \%$ better than in the 9 -sec control condition and $15 \%$ better than in the keyword condition. The difference among the three conditions was significant $[F(2,57)=12.78, M S e=$ 10.38], and the Newman-Keuls test indicated that each of the three means was significantly different from the others. The critical result here is that the relationship between the keyword and control (no-strategy) conditions is markedly different depending on how rapidly (and frequently) items are presented in the control condition.

The significant main effect of retention interval showed that forgetting did occur $[F(1,57)=37.29, M S e=1.22]$. A presentation rate $X$ retention interval ANOVA applied to List 1 scores gave no evidence of any difference in rates of forgetting ( $F<1$ for the interaction).

\section{DISCUSSION}

The main empirical generalization suggested by these experiments is that optimal presentation rates differ depending on whether or not the subject is attempting to use a complex mnemonic such as the keyword method. When the subject is attempting to use the keyword method, then a presentation rate as rapid as $\mathbf{4} \mathrm{sec}$ is faster than is optimal with the degree of keyword training used in this and most other studies of the keyword method. However, when subjects are not instructed in any special way, vocabulary learning proceeds much more rapidly if the study period is used to present the list more rapidly and more frequently. One cannot pinpoint optimal rates from these experiments, but the 2- to 4sec estimate given for PAL by Johnson (1964) and Calfee and Anderson (1971) seems plausible when no special study instructions are given. Using much slower rates to accommodate the requirements of the keyword method puts nonmnemonic control conditions at a serious disadvantage, just as the use of fast (e.g., 3-sec rates) would be disadvantageous for subjects in a keyword condition (although perhaps less so if more training were given). Either procedure would be misleading from a practical perspective, because nonlaboratory vocabulary learning situations are unlikely to impose such constraints (see Hall \& Fuson, 1986, for additional discussion of this point).

These findings imply that results of keyword experiments in which unusually slow rates have been imposed on the nonmnemomic as well as the mnemonic condition are of limited value regarding the utility of the keyword method in applied educational settings, and, in fact, may be quite misleading in that respect. Such experiments constitute a large proportion of the studies that have formed the basis for optimistic conclusions in various reviews (e.g., Pressley, Levin, \& Delaney, 1982) 
regarding the educational value of the keyword method. Evaluation of the educational utility of the keyword method will require experiments that do not have the built-in bias toward the keyword method that has characterized most such experiments to date.

\section{REFERENCES}

AtKInson, R. C. (1975). Mnemotechnics in second-language learning. American Psychologist, 30, 821-828.

BellezzA, F. S. (1981). Mnemonic devices: Classification, characteristics, and criteria. Review of Educational Research, 51, 247-275. BUgeLsKI, B. R. (1970). Words and things and images. American Psychologist, 25, 1002-1012.

CAlfee, R. C., \& ANDerson, R. (1971). Presentation rate effects in paired-associate learning. Journal of Experimental Psychology, 88, 239-245.

HALL, J. W., \& FUSON, K. C. (1986). Presentation rates in experiments on mnemonics. Journal of Educational Psychology, 78, 233-234.
Hall, J. W., Smith, T. A., Wegener, S. L., \& Underwood, B. J. (1981). Rate and frequency as determinants of learning with complete and discrete list presentation. Memory \& Cognition, 9, 360-367. Hall, J. W., Wilson, K. P., \& Patterson, R. J. (1981). Mnemotechnics: Some limitations of the mnemonic keyword method for the study of foreign language vocabulary. Journal of Educational Psychology, 73, 345-357.

HigBeE, K. L. (1977). Your memory: How it works and how to improve it. Englewood Cliffs, NJ: Prentice-Hall.

JoHnson, N. F. (1964). The functional relationship between amount learned and frequency vs. total time of exposure to verbal materials. Journal of Verbal Learning \& Verbal Behavior, 3, 502-504.

Pressley, M., LeVIn, J. R., \& Delaney, H. D. (1982). The mnemonic keyword method. Review of Educational Research, 52, 61-91.

WooD, G. (1967). Mnemonic systems in recall. Journal of Educational Psychology, 58, 1-27 (Monograph).

(Manuscript received for publication November 10, 1986.) 